\title{
Acute pandysautonomia and severe sensory deficit with poor recovery. A clinical, neurophysiological and pathological case study
}

\author{
JAN FAGIUS, ${ }^{*} \dagger$ CARL-EINAR WESTERBERG,${ }^{*}$ YNGVE OLSSON $\ddagger$ \\ From the Departments of Clinical Neurology*, Clinical Neurophysiology † and Neuropathology $\ddagger$, University \\ Hospital, Uppsala, Sweden
}

SUMMARY A patient with acute loss of autonomic functions and virtually all afferent functions of peripheral nerves is described. The course was chronic and the outcome fatal. The clinical course was followed with measurements of sensory thresholds and conduction velocities, autonomic tests and microneurographic recordings. Neuropathological changes were severe and localised in the peripheral nervous system. Previously reported similar cases were reviewed. It was concluded that acute pandysautonomia is a disorder similar to the Guillain-Barré syndrome; the course is often protracted and residual neurological deficit common.

Profound dysfunction of the autonomic nervous system with acute or subacute onset is a rare disease. Since the first case was reported in $1969^{12}$ a number of similar cases have been described, with some variation of the neurological deficit. In some cases main functions of both the sympathetic and parasympathetic system have been affected, ${ }^{2-6}$ others have shown a predominantly cholinergic dysautonomia, ${ }^{4-9}$ and still other patients have displayed loss of autonomic function together with other impairment of nervous function. ${ }^{10-12}$ Half of the reported cases have been children. The course is often protracted with slow improvement. The cause is unknown but an immunological disorder akin to the Guillain-Barré syndrome has been suggested.

The present report describes a patient with severe pandysautonomia and total loss of sensation with remarkably poor recovery. The patient was followed with extensive neurophysiological investigations throughout the course of the disease until his death 45 months after the onset. A post-mortem neuropathological examination was performed.

\section{Case report}

The patient, a previously healthy man, was 31 years old when in 1977 a malignant tumour of his left testis was

Address for reprint requests: Jan Fagius, MD, Department of Neurology, University Hospital, S-751 85 Uppsala, Sweden.

Received 21 February 1983

Accepted 19 March 1983 discovered. The tumour was removed and lymph glands were excised. The tumour was classified as a mixture of seminoma and embryonal carcinoma. No metastases were discovered in the lymph glands removed. The tumour was considered radically removed and no radiation was given. During the next six months the patient appeared healthy.

On 11 March 1978, two weeks following an upper respiratory tract infection, he developed severe itching of the hands, rapidly spreading to the whole body. Within two days the itching was replaced by an excruciating pain all over the body surface. He was simultaneously sweating profusely. His pain made necessary the use of opiate analgesics in doses causing respiratory depression during the following week, then the pain diminished and had disappeared on 21 March, when he arrived at the Department of Neurology, University Hospital, Uppsala. At that time he complained of intolerance to light, dryness of eyes and mouth, difficulty in swallowing solid food, heat intolerance and difficulty in emptying the bladder. On examination on 21 March hallucinations were noted, but the patient could communicate adequately. Both pupils were dilated, neither responding to light or accommodation. Corneal sensation was markedly decreased and corneal reflexes were absent. Eye movements were normal. A slight dysarthria was present. Touch sensation was normal all over the body but vibration and temperature senses appeared severely impaired and there were large areas of analgesia. There was marked extremity ataxia and total loss of tendon reflexes but no obvious muscle weakness. Body temperature was about $38^{\circ} \mathrm{C}$. No sweating at all was apparent. Bladder paresis was noted and an indwelling catheter had to be used. Resting heart rate varied between 120 and $160 /$ min but resting blood pressure was normal.

The following week he developed severe postural hypotension and fainted even in a semi-recumbent position. Sensation was totally lost for all modalities all over 
the body except that the patient could localise a stroking touch. Heart rate stabilised between 100 and 110. Mental functions normalised. Remaining symptoms were unchanged. Constipation did not become severe. Penile erections were totally absent.

Ophthalmologic examination on 4 April, revealed dilated pupils, nonreacting to light, and total absence of accommodation. A diluted solution of pilocarpine (1/8\%) caused longstanding pupillary constriction, indicating peripheral parasympathetic denervation. No test for adrenergic hypersensitivity was performed. During the following weeks bronchitis with stagnation of secretions was present; at bronchoscopy decreased sensation and reactivity of the bronchial mucosa was noted. During the same period a slight improvement of the neurological deficit occurred. Thus, from 2 May, the patient was able to empty his bladder. He could at that time sit without fainting but with a rapid fall of systolic blood pressure to about 70 $\mathrm{mmHg}$; he could counteract his fainting tendency with leg movements. One month later he could walk but not stand still without fainting. The ataxia improved slightly.

Laboratory analyses: The CSF protein content was normal on 21 March, but elevated at later analyses, to a maximum of $0.96 \mathrm{~g} / 1$ (normal value $<0.5 \mathrm{~g} / \mathrm{l}$ ). The cell content was normal. Repeated tests for porphyria were normal. Extensive laboratory analyses revealed no obvious cause of the neurological disease and no signs of recurrence of the testicular malignancy were found. ECG showed no abnormality except tachycardia.

Subsequent course: During the summer of 1978 the above symptoms were mainly unchanged, but nausea and sometimes profuse vomiting supervened. Radiography of the stomach and oesophagus revealed nothing abnormal. Patchy and migrating pains from different parts of the body occurred from spring 1979 . The pains were aching and stabbing. Combined treatment with carbamazepine, amitriptyline and thioridazin brought about some relief. Corneal ulceration occurred and was successfully treated. Fludrocortisone treatment led to some improvement of the postural hypotension.

In the summer of 1979 an abdominal mass was discovered and identified as a recurrence of his testicular malignancy. Radiation treatment and a combination of cytostatic drugs was given (vinca-alkaloids were not given). The abdominal tumour diminished, as shown by repeated computed tomograms of the abdomen, and there was no further enlargement during the rest of the patient's life. In 1980 recurrence of the cancer in the left inguinal region was treated successfully with radiation.

In August 1980 the patient developed compulsive drinking, leading to a severe water intoxication with loss of consciousness and grand mal seizures. He recovered and investigation of hypothalamic function with hormone analyses and CT of the brain showed no abnormalities.

The course of the neurological disease from autumn 1978 to the death of the patient on 27 December 1981 , was characterised by a chronic state of illness with some but extremely slow improvement. At the last clinical examination, on 12 November 1981, he was mentally normal. The pupils were dilated and nonreacting to light, but a tonic reaction was seen at accommodation attempts. Corneal sensation and corneal reflexes were entirely absent. The mouth was dry and mucosal sensation in the mouth was virtually absent. All sensory modalities were severely impaired, except on patchy areas of the face and the back, where a needle was perceived as sharp. Ataxia was still moderate in the arms and pronounced in the legs. No tendon reflexes could be elicited, but muscle strength was normal. Postural hypotension was marked with a systolic blood pressure of $65 \mathrm{mmHg}$ and a tendency to blackout after 2 minutes of standing. Sweating was noted only in patchy areas of the face. In summary, findings differed only slightly from those seen at regular examinations since autumn 1978.

On 27 December 1981, nausea and vomiting were markedly accentuated; he rapidly became severely ill and on arrival at hospital he was without measurable blood pressure or detectable peripheral pulses and died within two hours.

At necropsy a mass of adherent small intestines with stenosis and peritonitis was found. Metastases from the testis tumour were not apparent. The death of the patient was probably unrelated to the dysautonomia but indirectly related to the sensory loss, since the radiation-induced intestinal obstruction was not interpreted as such because of absence of abdominal pain.

\section{NEUROPHYSIOLOGICAL INVESTIGATIONS Methods}

Tests of cutaneous sensation. Quantitative measurements
of sensory thresholds were made for vibratory, tactile and of sensory thresholds were made for vibratory, tactile ando ing $100 \mathrm{~Hz}$ sine wave movements was used. The amplitude of the vibrating plastic probe was recorded by an accelerometer and displayed in $\mu \mathrm{m}$. Measurements were made on defined points of the hand, lower leg and foot Tactile sense was tested with a plastic probe giving $10 \mathrm{~Hz}$ rapid indentations to the pulp of the forefinger and big toe. The size of the probe movement was measured in $\mu \mathrm{m}$. Temperature sense was determined as the "warm-cold difference-limen" with a thermostimulator using the Peltier principle. Temperature change of the probe was read off with an accuracy of $0.5^{\circ} \mathrm{C}$. Measurements were made on hand and foot. The device was used also for quantitative assessment of pain sensation from heat and cold. Detailed descriptions of these methods have been presented in method studies. ${ }^{13-16}$

Nerve conduction measurements were made with standard techniques; ${ }^{17}$ for sensory conduction velocities averaging was applied.

Tests of autonomic function. Skin sympathetic effector organs were tested: sudomotor function by recording decrease of skin resistance (galvanic skin response, GSR) and vasoconstrictor function by monitoring digital pulse amplitude reduction at startle reaction following arousal stimuli. ${ }^{18}$ For these purposes $\mathrm{Ag} / \mathrm{AgCl}$ electrodes on the palm of the hand and the sole of the foot and photoelectric pulse plethysmograph on the forefinger and big toe were used, respectively.

Vagal function was tested on two occasions by recording ECG during a sudden change of position from lying to standing. The ratio between the $R-R$-intervals of the 30th and 15 th heart beat after the tilting was calculated, the 
"30-15-ratio". ${ }^{19}$ Values above 1.03 are regarded as normal; lower values indicate vagal damage. ${ }^{20}$ The Valsalva ratio, that is the quotient between the longest $R-R$-interval following and the shortest R-R-interval during a Valsalva manoeuvre ${ }^{21}$ was measured once. A Valsalva ratio above 1.21 is considered normal and values below 1.10 clearly indicate impaired vagal function. ${ }^{20}$ Postural hypotension was tested by blood pressure measurement in the lying position, immediately after standing up and after 2 minutes standing.

Microneurography. Tungsten microelectrodes, with a tip diameter of $1-5 \mu \mathrm{m}$, permit direct recording of naturally occurring nerve discharges from peripheral nerves in unanaesthetised man. ${ }^{22}$ Muscle spindle afferent activity and skin sensory impulses as well as sympathetic signals can be recorded. The technique has been described in detail previously. ${ }^{22}$

The median nerve at the elbow and the peroneal nerve at the fibular head were studied. The recording electrode was inserted through intact skin and a similar reference electrode was placed subcutaneously $1-2 \mathrm{~cm}$ away. Electrical stimuli delivered through the electrode were used to find the nerve. Normally, the responses to such stimuli serve as an aid to identify the nerve fascicle encountered-that is muscle twitches from stimulation of the muscle nerve fascicle and paraesthesiae within the innervation zone of the nerve from stimulation of a skin nerve fascicle. In normal subjects, afferent mechanoreceptor activity can easily be evoked by passive muscle stretches or taps and skin touch, respectively. This afferent activity also can be used for identification of the electrode site. Then spontaneously occurring sympathetic activity, which has different characteristics in skin and muscle fasci$\operatorname{cles}^{22}$ can be recorded following minor electrode adjustments. In normal subjects muscle nerve sympathetic activity occurs grouped in brief pulse-synchronous bursts of impulses with intervals of neural silence. ${ }^{23}$ Manoeuvres such as the Valsalva, deep breathing, or apnoea increases the outflow. ${ }^{24}$ Skin nerve sympathetic activity appears more irregularly, the burst has a longer duration and the discharges can be evoked by arousal stimuli, a sudden deep inspiration and emotional stress. ${ }^{25} 26$

The patient gave informed consent for the recordings.

\section{Results}

\section{EEG}

On 21 March 1978, the postcentral rhythm was 7-9 $\mathrm{Hz}$ and a slightly increased symmetrical theta activity was present. EEGs on three further occasions in spring 1978 and once in 1979 were normal.

\section{TESTS OF SENSATION}

(a) In the early phase of the disease vibratory sense was examined with a tuning fork only. The patient was unable to perceive such vibration throughout the entire course of the disease. From October 1979 quantitative measurement was performed and the extremely high values are shown in fig $1 \mathrm{~A}$.

(b) Touch sense was measured repeatedly through-
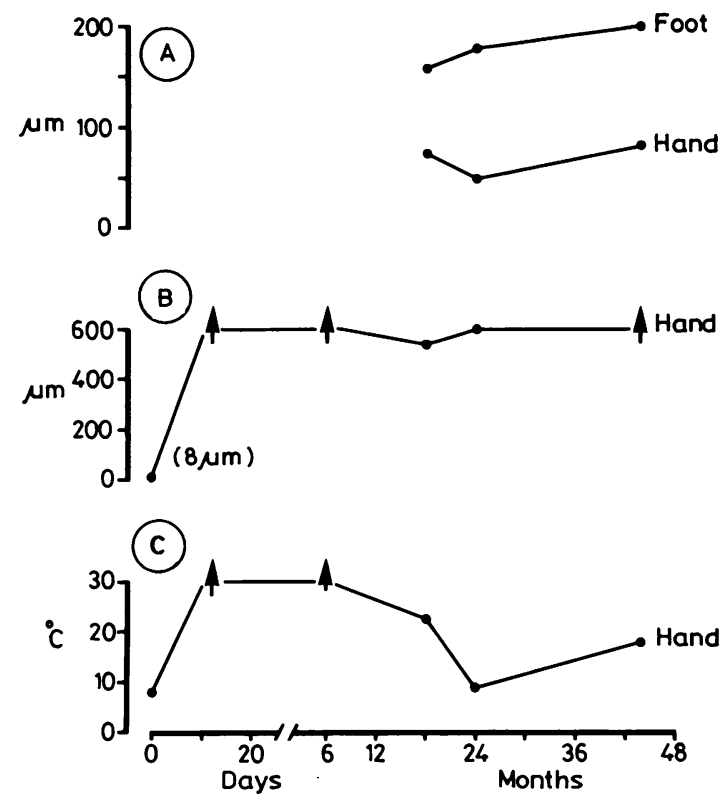

Fig 1 Sensory thresholds for vibration $(A)$, touch $(B)$, and temperature ( $C$-expressed as the "warm-cold difference limen"). The abscissa shows duration of disease. Arrows indicate that threshold exceeded upper limit of the device. Normal values related to the patient's age: Vibration hand: $0.60 \mu \mathrm{m}$; foot: $2.50 \mu \mathrm{m}$. Touch hand: $7.1 \mu \mathrm{m}$. Temperature hand: $1 \cdot 6^{\circ} \mathrm{C}$.

out the course of disease (fig 1B). The clinical impression of virtually normal touch sense when the patient first arrived on 21 March 1978, was confirmed by the test, but soon extremely high or non-measurable thresholds were noted and they remained unchanged.

(c) Temperature sense thresholds were also measured quantitatively from the early phase of the disease. As seen from fig $1 \mathrm{C}$ temperature sense was moderately impaired at the first examination, then very high thresholds were reached; later on some improvement occurred.

(d) Normal perception of heat and cold pain was present in the hands at the first examination on 22 March 1978, but from 4 April and during all following assessments no pain perception at all was present.

\section{NERVE CONDUCTION MEASUREMENTS}

(a) Sensory nerves. Sural nerve conduction velocity was normal in both legs on 21 March 1978, as was conduction time and amplitude of sensory potentials from the ulnar and median nerves at both wrists. From the next measurement attempt on 11 April 
and on all following eight attempts with regular intervals throughout the course no sensory potential at all could be evoked.

(b) Motor nerves. Moderate slowing of motor nerve conduction and delay of F-responses developed during the first three months of the disease. Thereafter the velocities remained unchanged. Needle electromyography was not performed in the early phase of the disease. In November 1981 the EMG was normal in hand muscles; in muscles of lower leg some motor unit potentials with moderate neurogenic changes were seen and a slight loss of motor units was found.

\section{TESTS OF AUTONOMIC FUNCTION}

Sudomotor function was not detected at any testing site on any occasion. Skin vasoconstriction was not seen during the first month of the disease, but reappeared in the hands, as shown in table 1 .

"30-15-ratio" was 0.84 and 0.94 in February 1979. In November 1981 the ratio at two tests was 1.06 and 1.12 . Valsalva ratio was 1.00 and 1.03 in November 1981.

Table 2 illustrates the persistent marked postural hypotension with fainting or lightheadedness within 2 minutes of immobile upright position during the entire course of the disease.

In October 1979 a $4 \%$ pilocarpine solution was injected intradermally in the left forearm (giving a wheal diameter of $6 \mathrm{~mm}$ ). Sweat pores were detected by application of $5 \%$ o-phthal-aldehyde in xylene, a highly sensitive sweat stain. ${ }^{27} \mathrm{~A}$ few stained spots appeared. The same amount of pilocarpine injected in the corresponding area of a control subject produced a confluent stained area of 20-25 mm diameter. The result indicates postganglionic denervation of sweat glands. ${ }^{28} 29$

\section{MICRONEUROGRAPHY}

Recordings were performed seven times during the disease. The left median nerve was studied five times (September 1978, February and March 1979, June 1980 and November 1981). The right peroneal nerve was investigated twice (September 1979 and November 1981).

(a) Muscle afferent activity: On all occasions at least two intraneural electrode positions in muscle nerve fascicles were obtained as evidenced by muscle twitches elicited by electrical stimuli of low intensity. At all recordings except those of November 1981 no muscle afferent activity could be seen, despite two or more muscle fascicle electrode sites at every recording attempt and despite strong stretching and tapping of the appropriate muscle. In November 1981 two electrode positions out of four in the median nerve showed a weak but clear multiunit afferent response. The discharge pattern is illustrated in fig 2, compared with the pattern from multi-unit activity in a normal nerve. In the peroneal nerve one electrode position of five displayed afferent signals from two or three units.

(b) Skin afferent activity: Paraesthesiae from the electrical stimulation were never perceived by the patient during the search for the nerve. Afferent

Table 1 Reduction of skin resistance (GSR) and skin vasoconstriction in hands and feet following startle stimuli

\begin{tabular}{|c|c|c|c|c|c|c|c|c|}
\hline \multirow[t]{2}{*}{ Date } & \multicolumn{4}{|l|}{$G S R$} & \multicolumn{4}{|c|}{ Vasoconstriction } \\
\hline & $\begin{array}{l}\text { Hands } \\
\text { Right }\end{array}$ & Left & $\begin{array}{l}\text { Feet } \\
\text { Right }\end{array}$ & Left & $\begin{array}{l}\text { Hands } \\
\text { Right }\end{array}$ & Left & $\begin{array}{l}\text { Feet } \\
\text { Right }\end{array}$ & Left \\
\hline 1978 March & 0 & - & - & - & - & 0 & - & - \\
\hline June & 0 & 0 & 0 & 0 & 0 & 0 & 0 & 0 \\
\hline Sept & 0 & 0 & 0 & 0 & weak & weak & 0 & 0 \\
\hline $1979 \mathrm{Feb}$ & 0 & 0 & 0 & 0 & weak & clear & 0 & 0 \\
\hline 1980 May & 0 & 0 & 0 & 0 & weak & weak & 0 & 0 \\
\hline 1981 Nov & 0 & 0 & 0 & 0 & weak & clear & 0 & 0 \\
\hline
\end{tabular}

$0=$ no response

weak $=$ weak response

clear $=$ clear response, not different from normal

$-=$ not performed.

Table 2 Systolic blood pressure, lying and standing. Mm mercury

\begin{tabular}{|c|c|c|c|c|c|c|c|}
\hline & $\begin{array}{l}\text { March } \\
1978\end{array}$ & $\begin{array}{l}\text { May } \\
1978\end{array}$ & $\begin{array}{l}\text { Sept } \\
1978\end{array}$ & $\begin{array}{l}\text { Oct } \\
1979\end{array}$ & $\begin{array}{l}\text { Jan } \\
1980\end{array}$ & $\begin{array}{l}\text { March } \\
1980\end{array}$ & $\begin{array}{l}\text { Nov } \\
1981\end{array}$ \\
\hline $\begin{array}{l}\text { Lying } \\
\text { Standing immediately } \\
\text { Standing } 2 \text { minutes }\end{array}$ & $\mathrm{F}^{130}$ & $\begin{array}{l}130 \\
F\end{array}$ & $\begin{array}{r}140 \\
60 \\
F\end{array}$ & $\begin{array}{r}180 \\
60 \\
45, F\end{array}$ & $\begin{array}{r}125 \\
90 \\
F^{90}\end{array}$ & $\begin{array}{r}120 \\
65\end{array}$ & $\begin{array}{r}135 \\
80 \\
65, \mathrm{~F}\end{array}$ \\
\hline
\end{tabular}

$F=$ fainting or lightheadedness 


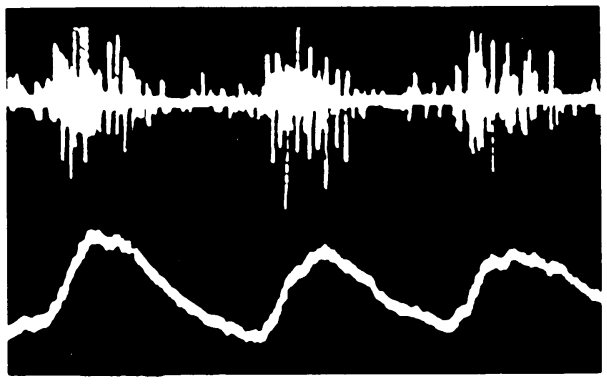

0.1s
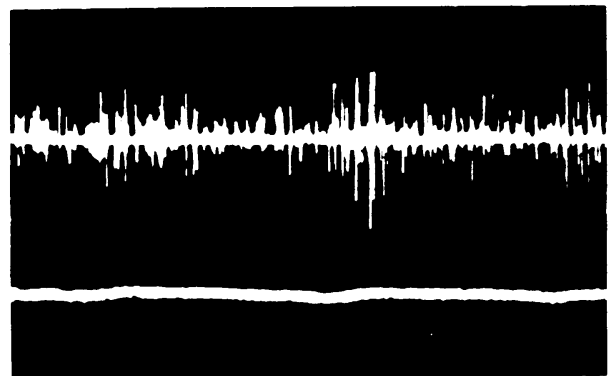

4

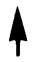

Fig 2 Multi-unit afferent signals recorded at microneurography from a muscle fascicle of the median nerve of a healthy" subject (left) and the last recording (Nov 1981) of the patient (right). Upper traces; original neurogram. Lower traces: mean voltage (integrated) neurogram. The difference is best seen in the mean voltage neurogram: distinct activity responding to rhythmic stretching of the appropriate muscle in recording from the normal subject and only minimal similar deflections from the base-line (arrows) in the patient recording. (NB: the discharges recorded depend on the technical quality of the recording, that is the intraneural site of the electrode; the patient recording shows the most intense activity ever seen during 7 recordings).

discharges were never seen at any recording attempt.

(c) Sympathetic activity: No sympathetic activity at all was seen at any of the recording attempts, despite repeated electrode adjustments and use of the manoeuvres normally evoking sympathetic discharges (see Methods) following every adjustment.

\section{NEUROPATHOLOGICAL FINDINGS Methods}

At necropsy the brain, spinal cord, sciatic and femoral nerves as well as cervical sympathetic trunk and the coeliac ganglion were removed and fixed by immersion in $10 \%$ formalin. After fixation the material was examined macroscopically and samples were taken for embedding in paraffin and epon. Sections were thereafter stained with routine neurohistological methods.

\section{Results}

The brain contained an old necrosis with partial resorption of the tissue, clusters of lymphocytes and astrocytic gliosis. It was located in the right rostral area of the hippocampus and measured about 10 $\mathrm{mm}$ in its longest diameter; otherwise no macroscopical abnormalities were detected in the cerebral hemispheres, the cerebellum and the pons. However, a moderate atrophy was present in the medulla oblongata and the spinal cord with an asymmetrical reduction of the dorsal columns particularly on the left side of the cord.

At all levels of the spinal cord the dorsal columns showed an almost complete loss of myelinated fibres associated with a moderate gliosis, that is, signs of severe tract degeneration. No detectable changes were present in the lateral and ventral columns; nor were there any clear reductions in the number of neurons in the ventral horn or in the intermediolateral nucleus (fig 3 ).

The dorsal root ganglia showed very severe changes with only a few remaining neurons (fig 4 ). All the others had disappeared and their locations were indicated by clusters of satellite cells. There was also an increase in collagen within the ganglia and in the adjacent part of the roots and nerve.

The dorsal roots were much damaged with severe reduction in myelinated fibres, increase in collagen formation and the presence of small clusters of mononuclear inflammatory cells mainly lymphocytes (fig 5). These cells were present both in the roots themselves and in the covering sheaths. Slight changes of basically the same nature were also present in the ventral roots but on the whole the great majority of their fibres remained.

The sciatic nerve showed profound changes with a marked reduction in myelinated fibres, proliferation of Schwann cells, fibrocytes and mast cells as well as endoneurial fibrosis. The femoral nerve showed similar but less marked abnormalities.

A few small samples were also available from the peripheral autonomic nervous system. From the cervical sympathetic trunk no neurons were present (sampling error); the nerves contained densely packed Schwann cells presumably indicating a tissue response to injury. No lymphocytes were present. 


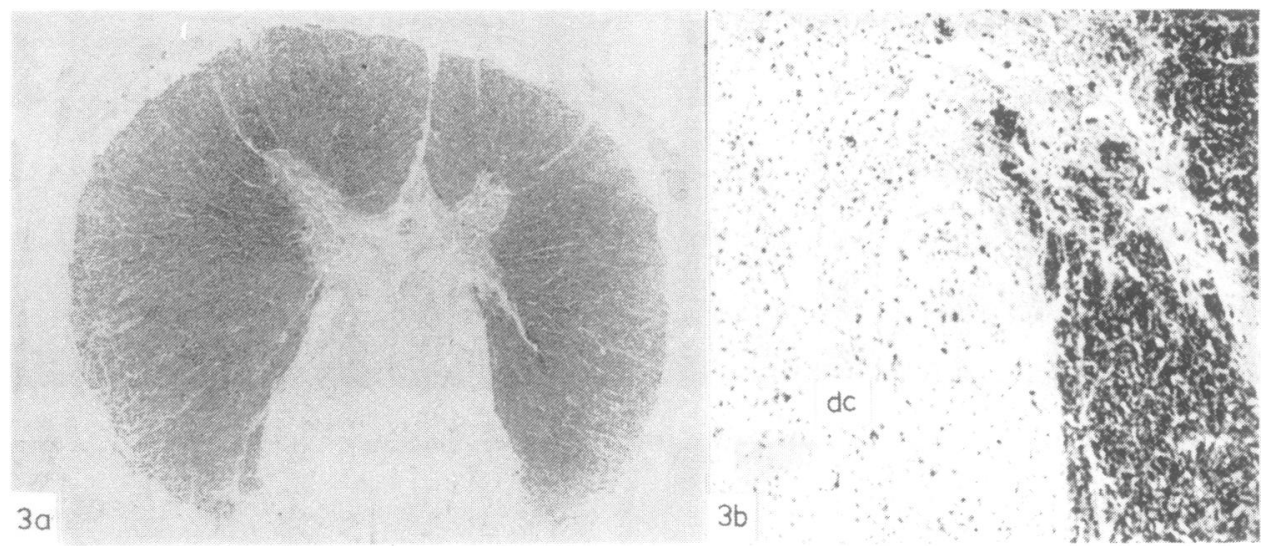

Fig 3 Cross section from the spinal cord. In the myelin stained preparation (Luxol fast blue) the lateral and ventral areas have a normal appearance whereas the dorsal tracts are heavily damaged (white areas) due to loss of myelinated fibres). (a) Overall view (magnification $\times 8)(b)$ Higher magnification $(\times 50)$ from the transition between the lateral and dorsal areas of the cord. Note a few remaining myelinated fibres in the dorsal columns (dc).
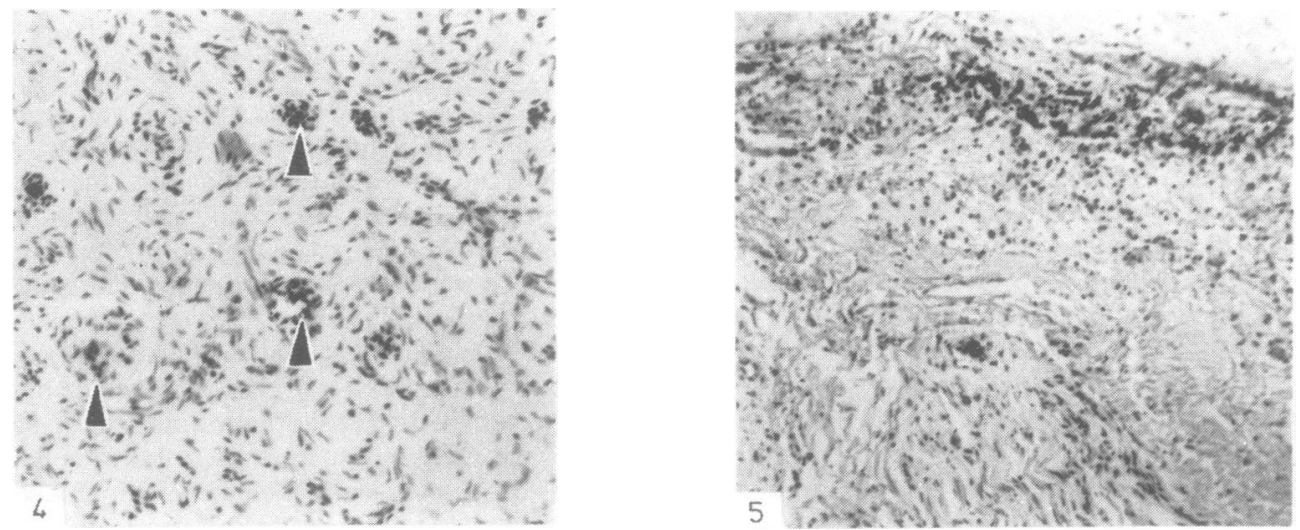

Fig 4 Section from a dorsal root ganglion stained with a haematoxylin and eosin. All the nerve cell bodies have disappeared and their positions have been replaced by clusters of satellite cells. Examples of such "nodules of Nageotte" are indicated by arrow heads $(\times 65)$.

Fig 5 Section from a dorsal root stained with luxol fast blue and cresyl violet. Note the presence of numerous rounded cell nuclei most probably of lymphocytic origin. All the myelin has disappeared $(\times 60)$.

Basically similar mild changes were present in the coeliac ganglion. In this ganglion no obvious abnormalities were seen with regard to the shape and staining properties of the neurons.

\section{Discussion}

The patient acutely developed a state of pandysautonomia. Severe postural hypotension, anhidrosis and paralysis of skin vasomotor reflexes represent loss of sympathetic function while parasympathetic impairment was indicated by non-reacting pupils, paresis of accommodation, decreased lacrimation, dry mouth and mucosal surfaces, vomiting probably due to decreased motility of the upper alimentary tract, bladder paresis and penile impotence. Simultaneously a polyneuropathy became apparent with severe or total loss of virtually all afferent functions including proprioception but only subclinical motor involvement.

\section{Site of damage}

CNS involvement relevant to the clinical symptoms and signs was probably not present. The initial trans- 
ient hallucination was explained as an opiate withdrawal reaction. EEG was essentially normal. The episode with water intoxication was considered accidental due to nausea and severe dryness of mouth; follow-up investigation displayed no underlying CNS abnormality.

The concomitant onset of a peripheral neuropathy suggests that the autonomic dysfunction also was localised peripherally. Denervation hypersensitivity of the pupils and the lack of sweating following local application of pilocarpine ${ }^{28} 29$ are signs of postganglionic denervation. The other autonomic tests do not discriminate between a pre- and postganglionic injury. This is true also for the lack of detectable sympathetic activity at microneurography.

Sensory loss was global. The absence of sensory potentials at all measurement sites at attempts to determine conduction velocities, the extremely high sensory thresholds, the lack of paraesthesiae from electrical stimuli and the lack of sensory discharges at microneurography are consistent with the clinical picture and suggest severe damage to all types of peripheral sensory fibres. Due to the lack of paraesthesiae from electrical stimulation at microneurography no evidence is present that a skin fascicle was ever encountered. However, judging from experiences in normal subjects and patients with polyneuropathy,,$^{182230}$ it is improbable that skin fascicles should be entirely missed at five recording attempts in the median nerve with two or more intraneural electrode positions on every occasion. Thus, the lack of paraesthesiae and lack of sensory signals should be interpreted as a sign of loss of peripheral sensory nerve function. There also was striking absence of muscle spindle afferent activity (and probably every kind of proprioception) corresponding to the patient's marked ataxia and loss of tendon reflexes.

The itching followed by severe pain and hyperhidrosis during the initial phase of the disease may have been due to extensive positive phenomena from peripheral $\mathrm{C}$ fibres preceding loss of function. Itch and pain are known to be subserved by afferent $C$ fibres, though the precise relationship between the two modalities is unknown. ${ }^{31} \mathrm{~A}$ contributory cause to the severity of the pain may be opening of "gates" due to loss of skin and muscular afferent activity.

Transient hyperhidrosis followed by anhidrosis has been reported previously ${ }^{4}$ and may reflect irritation of sympathetic $\mathrm{C}$ fibres. The transient tachycardia at admission may represent an impaired vagal function or a decreased inhibitory baroreflex activity resulting in increased sympathetic outflow, which was recently shown for patients with transient tachycardia and hypertension in the Guillain-Barré syndrome. ${ }^{32}$
Some improvement, though minor and extremely slow, occurred after the initial phase. Improved temperature sense of the hand (fig $1 \mathrm{C}$ ), reappearing skin vasomotor responses in the hand (table 1), signs of improved vagal influence on the heart and weak muscle nerve afferent activity on the last occasion of microneurography are consistent with the patient's reports about minor subjective improvement. The migrating pains appearing half a year after the onset may represent reinnervation phenomena of sensory fibres. The slightly improved postural hypotension (table 2) is difficult to assess, since fludrocortisone treatment was used and a compensatory increase of blood volume must be considered.

With the exception of the hippocampal necrosis, which had no apparent clinical correlation, the neuropathological changes were restricted to the peripheral nervous system (and the dorsal columns, which should be regarded as extensions of peripheral neurons to the spinal cord). The intermediolateral columns were normal, in contrast to cases with progressive autonomic failure of central origin as described by Shy \& Drager. ${ }^{33}$ The localisation and severity of the histological changes are consistent with the clinical and neurophysiological findings. The preservation of the coeliac ganglion may account for the absence of severe constipation.

\section{Possible cause of the disease}

The aetiology of the disorder is not known. Diabetes or amyloidosis was not present and onset.and course are not consistent with disorders causing chronic progressive peripheral autonomic failure. Botulism may sometimes be dominated by autonomic failure ${ }^{34}$ but the adrenergic and sensory involvement, course and pathological findings preclude this possibility.

Autonomic neuropathy as a remote effect of cancer must be considered..$^{35-39}$ The patient was treated for a malignant disease, which relapsed 18 months after the onset of the neurological disorder. However, some facts make a remote effect of cancer as the dominant determinant of the syndrome improbable: the acute onset, occurring at a time when the malignancy appeared removed, and the chronic, non-progressive course with slight improvement despite relapse of the cancer.

Most previous authors have suggested that the dysautonomia may be an acute immunological damage to peripheral fibres of the autonomic nervous system. This suggestion is supported by elevated CSF protein content without pleocytosis in a few of the reported cases. Autonomic involvement is Common even in more typical cases of the Guillain-Barré syndrome $e^{40-42}$ and experimental autonomic neuropathy has been described..$^{434}$ The acute onset two weeks after a respiratory tract infec- 
Table 3 Features of previous cases and present case of acute pandysautonomia

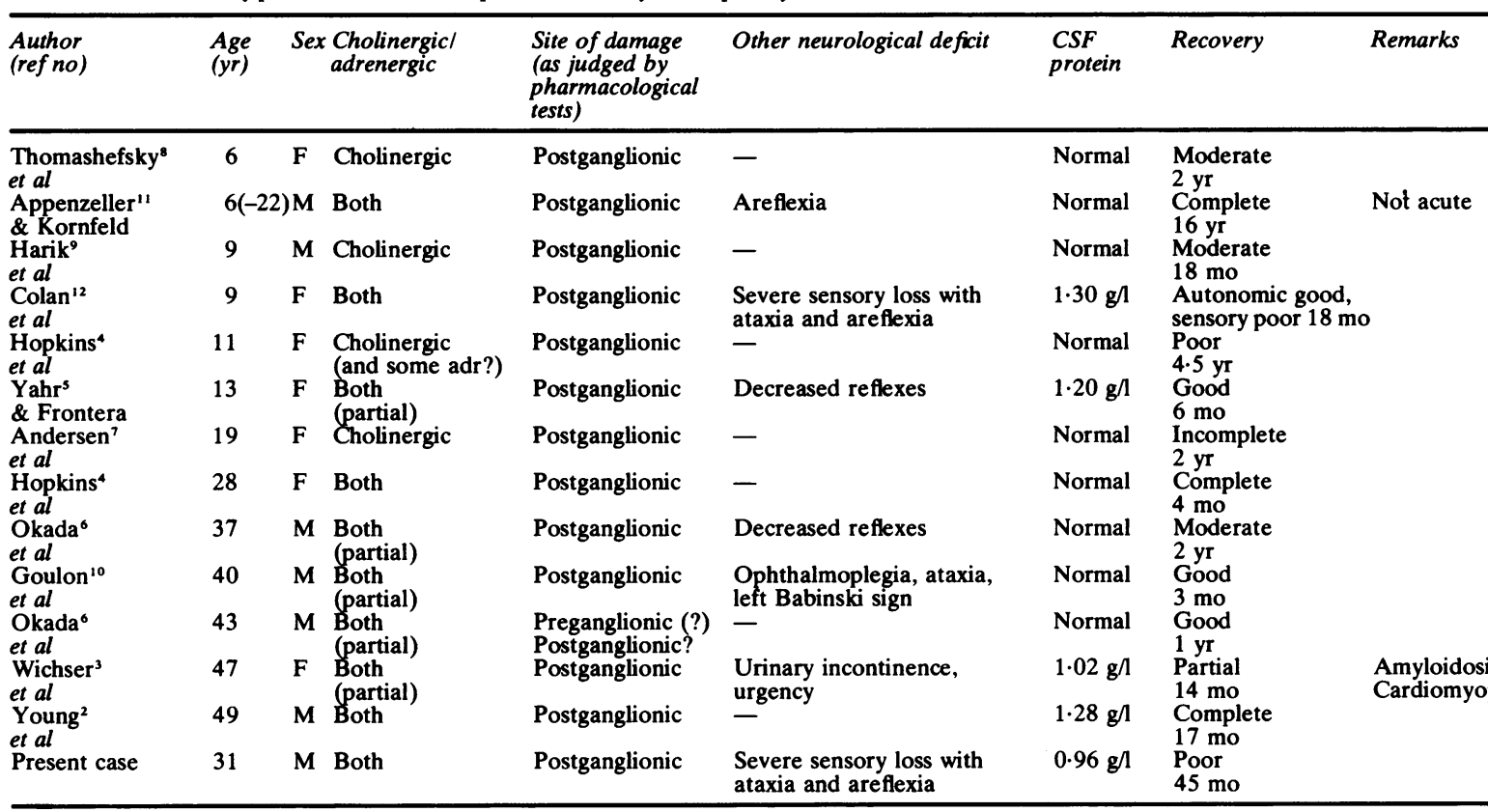

tion, the concomitant polyneuropathy and the elevated CSF protein level in the present patient make an aetiology similar to that of the Guillain-Barré syndrome likely.

The previously reported cases of acute and severe loss of autonomic function are summarised in table 3 . Nine cases have shown pandysautonomia and four a predominant or pure involvement of cholinergic (parasympathetic and sudomotor) functions. The patient reported by Colan et al ${ }^{12}$ had sensory loss as had our patient; otherwise signs of somatic polyneuropathy were not common. The present report is to our knowledge the first with neuropathological data (more than sural nerve biopsy) included. Since the main histological changes were situated in peripheral nerves or their central extensions in the spinal cord, it is of particular interest to note that almost all previous cases have shown one or more signs of denervation hypersensitivity. Case 2 of Okada $e^{a}$ al $^{6}$ is labelled preganglionic but there were some signs of denervation hypersentivity and the authors did not preclude an incomplete postganglionic lesion.

As suggested by table 3 and by the present case, acute profound impairment of autonomic function is probably a peripherally localised disorder like the Guillain-Barré syndrome, often with a protracted course and with a high percentage of residual dysfunction.
This work was supported by the Swedish Medical Research Council, grant no B81-14X 03546-10 B and the Swedish Society of Medical Sciences.

\section{References}

1 Young RR, Asbury AK, Adams RD, Corbett JL. Pure pan-dysautonomia with recovery. Trans Am Neurol Assoc 1969;94:355-7.

2 Young RR, Asbury AK, Corbett JL, Adams RD. Pure pan-dysautonomia with recovery. Description and discussion of diagnostic criteria. Brain 1975;98:61336.

${ }^{3}$ Wichser J, Vijayan N, Dreyfus PM. Dysautonomia-its significance in neurologic disease. Calif Med 1972;117:28-37.

${ }^{4}$ Hopkins A, Neville B, Bannister R. Autonomic neuropathy of acute onset. Lancet 1974;1:769-71.

5 Yahr MD, Frontera AT. Acute autonomic neuropathy. Arch Neurol 1975;32:132-3.

${ }^{\circ}$ Okada F, Yamashita I, Suwa N. Two cases of acute pandysautonomia. Arch Neurol 1975;32:146-51.

${ }^{7}$ Andersen O, Lindberg J, Modigh K, Reske-Nielsen E. Subacute dysautonomia with incomplete recovery. Acta Neurol Scand 1972;48:510-9.

${ }^{8}$ Thomashefsky AJ, Horwitz SJ, Feingold MH. Acute autonomic neuropathy. Neurology (Minneap) 1972;22:251-5.

${ }^{9}$ Harik SI, Ghandour MH, Farah FS, Afifi AK. Postganglionic cholinergic dysautonomia. Ann Neurol 1977;1:393-6. 
${ }^{10}$ Goulon M, Nouailhat F, Grosbuis S, Gajdos Ph. Hypotension orthostatique à pouls invariable. Etude hémodynamique d'une neuropathie amyloide et d'une forme idiopathique transitoire. Rev Neurol (Paris) 1971;125:257-72.

"Appenzeller O, Kornfeld M. Acute pandysautonomia. Clinical and morphological study. Arch Neurol 1973;29:334-9.

${ }^{12}$ Colan RV, Snead OC III, Oh SJ, Kashlan MB. Acute autonomic and sensory neuropathy. Ann Neurol 1980:8:441-4.

${ }^{13}$ Goldberg JM, Lindblom U. Standardised method of determining vibratory perception thresholds for diagnosis and screening in neurological investigation. $J$ Neurol Neurosurg Psychiatry 1979;42:793-803.

${ }^{14}$ Lindblom U. Touch perception threshold in human glabrous skin in terms of displacement amplitude on stimulation with single mechanical pulses. Brain Res 1974;82:205-10.

${ }^{15}$ Fruhstorfer H, Lindblom U, Schmidt WG. Method for quantitative estimation of thermal thresholds in patients. J Neurol Neurosurg Psychiatry 1976;39:1071-5.

${ }^{16}$ Fagius J, Wahren LK. Variability of sensory threshold determination in clinical use. $J$ Neurol Sci 1981;51:11-27.

${ }^{17}$ Kaeser HE. Nerve conduction velocity measurements. In: Vinken PJ and Bruyn GW, eds. Handbook of Clinical Neurology. Amsterdam: North-Holland Publishing Company 1970;7:116-96.

${ }^{18}$ Fagius J, Wallin BG. Sympathetic reflex latencies and conduction velocities in patients with polyneuropathy. J Neurol Sci 1980;47:449-61.

${ }^{19}$ Ewing DJ, Campbell IW, Murray A, Neilson JMM, Clarke BF. Immediate heart-rate response to standing: simple test for autonomic neuropathy in diabetes. Br Med J 1978;I:145-7.

${ }^{20}$ Campbell IW, Ewing DJ, Clarke BF. Tests of cardiovascular reflex function in diabetic autonomic neuropathy. In: Gries FA, Freund HJ, Rabe F and Berger $\mathrm{H}$, eds. Aspects of autonomic neuropathy in diabetes. Stuttgart: Georg Thieme Verlag 1980:61-8.

${ }^{21}$ Levin AB. A simple test of cardiac function based upon the heart rate changes induced by the Valsalva maneuver. Am J Cardiol 1966;18:90-9.

${ }^{22}$ Vallbo $\AA \mathrm{B}$, Hagbarth KE, Torebjörk HE, Wallin BG. Somatosensory, proprioceptive, and sympathetic activity in human peripheral nerves. Physiol Rev 1979;59:919-57.

${ }^{23}$ Delius W, Hagbarth KE, Hongell A, Wallin BG. General characteristics of sympathetic activity in human muscle nerves. Acta Physiol Scand 1972a;84:65-81.

${ }^{24}$ Delius W, Hagbarth KE, Hongell A, Wallin BG. Manoeuvres affecting sympathetic out flow in human muscle nerves. Acta Physiol Scand 1972b;84:82-94.

${ }^{25}$ Hagbarth KE, Hallin RG, Hongell A, Torebjörk HE, Wallin BG. General characteristics of sympathetic activity in human skin nerves. Acta Physiol Scand
1972;84:164-76.

${ }^{26}$ Delius W, Hagbarth KE, Hongell A, Wallin BG. Manoeuvres affecting sympathetic outflow in human skin nerves. Acta Physiol Scand 1972c;84:177-86.

${ }^{27}$ Juhlin L, Shelley WB. A stain for sweat pores. Nature 1967;213:408.

${ }^{28}$ Hyndman OR, Wolkin J. The pilocarpine sweating test. I. A valid indicator in differentiation of preganglionic and postganglionic sympathectomy. Arch Neurol Psychiat 1941;45:992-1006.

${ }^{29}$ Koelle GB. Parasympathomimetic agents. In: Goodman LS and Gilman A, eds. The pharmacological basis of therapeutics. London, Toronto: The Macmillan Company 1970:466-77.

${ }^{30}$ Fagius J. Microneurographic findings in diabetic polyneuropathy with special reference to sympathetic nerve activity. Diabetologia 1982;23:415-20.

${ }^{31}$ Torebjörk HE, Ochoa JL. Pain and itch from C fiber stimulation. Soc Neurosci Abstr 1981;7:228.

${ }^{32}$ Fagius J, Wallin BG. Microneurographic evidence of excessive sympathetic outflow in the Guillain-Barré syndrome. Brain 1983; in press.

${ }^{33}$ Shy GM, Drager GA. A neurological syndrome associated with orthostatic hypotension. Arch Neurol 1960;2:511-27.

34 Jenzer G, Mumenthaler M, Ludin HP, Robert F. Autonomic dysfunction in botulism B: A clinical report. Neurology (Minneap) 1975;25:150-3.

${ }^{35}$ Ivy HK. Renal sodium loss and bronchogenic carcinoma. Arch Intern Med 1961;108:47-55.

${ }^{36}$ Siemsen JK, Meister L. Bronchogenic carcinoma associated with severe orthostatic hypotension. Ann Intern Med 1963;58:669-76.

${ }^{37}$ Thomas JP, Shields R. Associated autonomic dysfunction and carcinoma of the pancreas. $\mathrm{Br} M e d \mathrm{~J}$ 1970;4:32.

${ }^{38}$ Park DM, Johnson RH, Crean GP, Robinson JF. Orthostatic hypotension in bronchial carcinoma. $\mathrm{Br}$ Med J 1972;3:510-1.

${ }^{39}$ Chiappa KH, Young RR. A case of paracarcinomatous pandysautonomia. Neurology (Minneap) 1973;23: 423.

${ }^{40}$ Birchfield RI, Shaw CM. Postural hypotension in the Guillain-Barré syndrome. Arch Neurol 1964;10:149-57.

${ }^{41}$ Lichtenfeld P. Autonomic dysfunction in the GuillainBarré syndrome. Am J Med 1971;50:772-80.

${ }^{42}$ Tuck RR, McLeod JG. Autonomic dysfunction in Guillain-Barré syndrome. J Neurol Neurosurg Psychiatry 1981;44:983-90.

${ }^{43}$ Appenzeller O, Arnason BG, Adams RD. Experimental autonomic neuropathy: An immunologically induced disorder of reflex vasomotor function. J Neurol Neurosurg Psychiatry 1965;28:510-5.

44 Tuck RR, Pollard JD, McLeod JG. Autonomic neuropathy in experimental allergic neuritis. An electrophysiological and histological study. Brain 1981;104:187-208. 